\title{
Kawasaki Disease: A 10-Year Experience
}

\author{
Yelda Esencan Turkmenoglu' (D), Ahmet Irdem² (D), Soner Sazak' (i), Chinara Esedoval (D), Emine Turkkan ${ }^{3}$ (D, \\ Omer Faruk Beser ${ }^{4}$ (D)
}

'Department of Pediatrics, Okmeydanı Education and Training Hospital, İstanbul, Turkey

2Department of Pediatrics, Pediatric Cardiology, Okmeydanı Education and Training Hospital, İstanbul, Turkey

${ }^{3}$ Department of Pediatrics, Pediatric Hematology, Okmeydanı Education and Training Hospital, İstanbul, Turkey

${ }^{4}$ Department of Pediatrics, Pediatric Gastroenterology, Okmeydanı Education and Training Hospital, İstanbul, Turkey

ORCID iDs of the authors: Y.E.T. 0000-000I-7472-8748; A.I. 0000-0002-2565-5674; S.S. 0000-0003-0233-6950; C.E. 0000-0002-58031438; E.T. 0000-0002-5126-7843; O.F.B. 0000-0003-1927-7256.

Cite this article as: Esencan Turkmenoglu Y, Irdem A, Sazak S, Esedova C, Turkkan E, Beser OF. Kawasaki Disease: A I0-Year Experience. Cyprus J Med Sci 2021; 6(I): 18-23.

\section{BACKGROUND/AIMS}

Kawasaki disease (KD) is an acute multisystemic vasculitis that manifests with prolonged fever commonly in children and involves medium-sized vessels. Coronary artery aneurysm occurs in 15\%-25\% of untreated patients. This study aims to evaluate the demographic, clinical, and laboratory characteristics as well as the treatment of patients with KD who were followed up in our clinic for 10 years.

\section{MATERIAL and METHODS}

Patients who were hospitalized with the diagnosis of KD between January 2009 and January 2019 in our hospital were evaluated on the basis of the patient records. Patients meeting at least four of the principal KD criteria were categorized as complete KD (cKD), and patients meeting fewer criteria were categorized as incomplete KD. Demographic characteristics and clinical, laboratory, and echocardiography $(\mathrm{ECHO})$ findings were evaluated.

\section{RESULTS}

Of the 36 patients (aged 4-62 months) involved in this study, 23 (63.9\%) were male, and 30 (83.3\%) were diagnosed within the first 10 days of their sickness. KD mostly occurred in children aged 12-60 months (66.7\%). cKD was observed in 19 patients, and $84.2 \%$ of them were aged between 12 and 60 months. ECHO showed coronary artery involvement in nine patients-eight of whom were male-and mitral insufficiency in three patients. Intravenous immunoglobulin treatment was administered twice in seven patients, one of them developed macrophage activation syndrome.

\section{CONCLUSION}

KD should be considered in cases of prolonged fever in children, and the diagnostic criteria should be examined carefully, and if diagnosed, patients should be given the correct treatment without any delay.

Keywords: Children, Kawasaki disease, macrophage activation syndrome

\section{INTRODUCTION}

Kawasaki disease (KD) is an acute febrile multisystemic vasculitis generally seen in children aged $<5$ years. The etiology of the disease is still unknown. It involves medium-sized vessels and manifests itself with prolonged fever and mucocutaneous symptoms $(\mathrm{I}, 2)$. In untreated cases, coronary artery aneurysm (CAA) develops with a frequency of $15 \%-25 \%$. The incidence of KD varies widely, depending on the geographical region and ethnicity; for example, in Japan, the annual incidence has been reported to be 309 in 100,000 children aged 0-4 years, whereas in the United States, the annual incidence is 25 in 100,000, and in England, it is 4 or 5 in 100,000 children (3-5).

The acute period in KD is usually defined as the first 10 days, and during this period, high fever is accompanied with certain symptoms that comprise the current diagnostic criteria, including bilateral nonpurulent conjunctivitis; cherry-red, cracked lips or strawberry tongue; cervical lymphadenomegaly $>1.5 \mathrm{~cm}$; nonvesiculobullous maculopapular or erythematous rash; as well as induration and erythema of the hands and feet $(1,2,6)$. However, not all of the findings appear at the same time in KD; the symptoms are observed for a short time, and some findings regress or disappear 
by the time of diagnosis. According to the American Heart Association (AHA), complete KD (cKD) is diagnosed when four of these criteria are evident with fever lasting $\geq 4$ days. The usual diagnostic criteria for KD are not sufficient for incomplete KD (iKD) cases with fever meeting only two or three diagnostic criteria. In such cases, the diagnosis of KD is supported by echocardiography $(E C H O)$ in the presence of pathological appearance in the coronary arteries, pericardial effusion, or valve involvement. For such cases, supportive laboratory criteria were recommended by AHA for early diagnosis and initiation of treatment in patients meeting two or three principal criteria and having normal $\mathrm{ECHO}$ findings in the acute phase. In the presence of C-reactive protein (CRP) $>3 \mathrm{mg} / \mathrm{dl}$ and/or erythrocyte sedimentation rate (ESR) $>40 \mathrm{~mm} / \mathrm{h}$ in these patients, these supporting laboratory criteria (white blood count [WBC] $>15.000$ per $\mathrm{mm}^{3}$, anemia by age, platelet $>450,000$ per $\mathrm{mm}^{3}$ after the seventh day, serum albumin $<3.0 \mathrm{~g} / \mathrm{dl}$, alanine aminotransferase $[A L T]>40 \mathrm{U} / \mathrm{L}$, and urine $\mathrm{WBC}>10$ per high power field) should be checked, and if the patients meet three or more of such criteria, they should be diagnosed with incomplete $\mathrm{KD}$, treated accordingly, and monitored with $\mathrm{ECHO}(1,6)$.

Therefore, this study aimed to evaluate the demographic, clinical, and laboratory characteristics of patients with KD who had been followed up at our clinic for 10 years and to evaluate the treatment and follow-up results of these patients.

\section{MATERIAL and METHODS}

For the study, the files of the patients who were hospitalized with the diagnosis of KD at the Pediatric Clinic of hospital between January 2009 and January 2019 were retrieved from the hospital records, and those who did not meet the diagnostic criteria were excluded from the study. Age, gender, admission, duration of fever, physical examination, and laboratory findings of the patients as well as the treatments provided were evaluated retrospectively. Patients meeting at least four diagnostic criteria for KD were categorized as CKD cases, whereas those meeting two or three principal criteria for KD and who were positive for $\mathrm{KD}$ in $\mathrm{ECHO}$ or those with $\mathrm{ESR}>40 \mathrm{~mm} / \mathrm{h}$ and CRP positivity who met three or more supporting laboratory criteria (anemia by age, leukocytosis, thrombocytosis after the seventh day, sterile pyuria, hypoalbuminemia, and ALT elevation) were considered to have $\operatorname{iKD}(1,6)$. The first day of the onset of fever was accepted as the onset of the disease, and the time to diagnosis was accepted as the period from the onset of fever to the time diagnosis was made. The patients who were diagnosed within the first 10 days were considered to have acute $\mathrm{KD}$, and those diagnosed after 10 days were considered to have subacute KD.

\section{Main Points:}

- Kawasaki disease is a multisystemic disease associated with fever.

- $\quad$ Finding on Echocardiography is valuable for the diagnosis of Kawasaki disease, but it does not always accompany. The risk of coronary pathology is higher at younger ages.

- Early diagnosis and treatment positively affects the prognosis of the disease.
In $\mathrm{ECHO}$ according to the Boston formula, $z$ score $>2.5$ or coronary artery internal lumen diameter (ILD) $>3 \mathrm{~mm}$ in children aged $<5$ years and an ILD $>4 \mathrm{~mm}$ in those aged $>5$ were accepted as dilatation or small aneurysm. Enlargement of the coronary artery segment by $<1.5$-fold was considered dilatation, and its enlargement by $\geq 1.5$-fold was accepted as an aneurysm $(1,7)$. Patients with coronary artery dilatation greater than normal and those with no segmental aneurysm were considered to have coronary artery ectasia. Brightness in coronary arteries and mitral and aortic valve regurgitation were evaluated as findings to support the KD diagnosis (7). $\mathrm{ECHO}$ was repeated within 2 weeks after the onset of the disease and at the fourth week. All patients diagnosed with KD received a single dose of intravenous immunoglobulin (IVIG) $2 \mathrm{~g} / \mathrm{kg}$, continuous infusion for 12 hours, and acetylsalicylic acid (ASA) at the dose of $80-100 \mathrm{mg} / \mathrm{kg} /$ day for a few days and then $5 \mathrm{mg} /$ $\mathrm{kg} /$ day for 4-6 weeks. Prolonged high fever lasting for 36 hours after IVIG and ASA administration was considered a nonresponse to treatment. Comparisons were made between $\mathrm{ECHO}$ findings, age, gender, leukocyte count, hemoglobin $(\mathrm{Hb})$ levels, platelet count, ESR, CRP, albumin, and aspartate aminotransferase (AST) and ALT levels. Ethics committee approval was received for this retrospective study from the Ethics Committee of our hospital (approval date: 08/01/2019, approval number: 4867077I-5|4.10).

\section{Data Analysis}

The research data and variables were analyzed with the Statistical Package for the Social Sciences 22.0 software package (IBM Corporation, Armonk, NY, USA) and MedCalc 14 (MedCalc Software, Ostend, Belgium). Shapiro-Wilk test and variance homogeneity were evaluated by Levene's test. Independent samples t-test was used with bootstrap results, and Mann-Whitney $U$ test was used with Monte Carlo results for the comparison of two independent groups according to quantitative data. For the comparison of categorical variables, Pearson chi-square and Fisher exact tests were used. The receiver operating characteristic curve was used to reveal the true positive rate (sensitivity) against the false positive rate (specificity) for all possible cutoff values calculated for group variables as well as the positive and negative predictive valves. The quantitative variables are presented in tables as mean \pm standard deviation and median range (maximum-minimum), and categorical variables are shown as $n$ (\%). The variables were examined at a 95\% confidence level, and a $p$-value $<.05$ was accepted as significant.

\section{RESULTS}

Medical records of 51 patients hospitalized with the diagnosis of KD were examined; 15 patients were excluded from the study because they did not meet the AHA diagnostic criteria, and the remaining 36 patients were included in the analysis. A total of 23 of the patients (63.9\%) were male; the male-tofemale ratio was $1: 77$. The ages of the patients ranged from 4 months to 62 months, with a mean age of $29.5 \pm 19.129$ months (Table I).

The distribution of patients by the date of diagnosis showed that five patients (13.8\%) were diagnosed with KD in 2009 and five were diagnosed in 2010, two (5.5\%) in 2011, two in 2012, one $(2.7 \%)$ in 2013 , six $(16.6 \%)$ in 2014 , three $(8.3 \%)$ in 2015 , four $(11.1 \%)$ 
in 2016 , five ( $13.8 \%)$ in 2017 , and three $(8.3 \%)$ in 2018 . The distribution of the patients by the months in which they presented to the hospital revealed that they most frequently presented to the hospital in July $(19.4 \%, \mathrm{n}=7$ ) (Figure I).

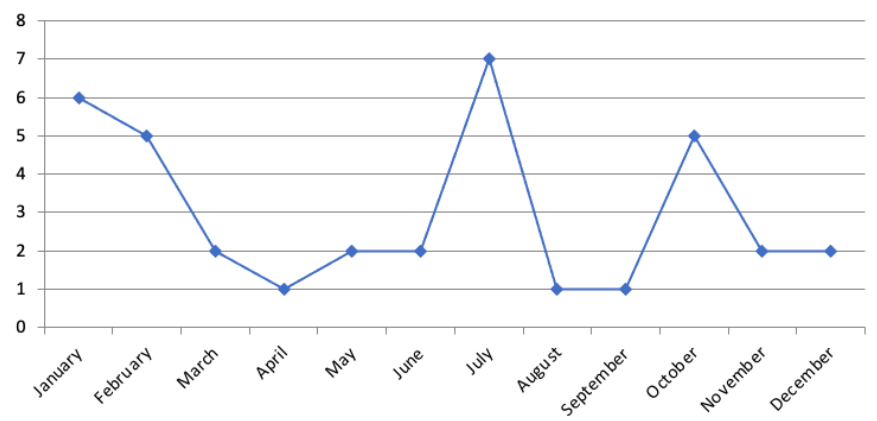

FIGURE I. Seasonal distribution of patients

TABLE I. Age and gender distribution of patients

\begin{tabular}{|c|c|c|c|c|c|c|}
\hline & & & \multicolumn{3}{|c|}{ Age (months) } & \multirow[b]{2}{*}{ Total } \\
\hline & & & $\begin{array}{c}0-I I \\
\text { months }\end{array}$ & $\begin{array}{c}12-60 \\
\text { months }\end{array}$ & $\begin{array}{c}60+ \\
\text { months }\end{array}$ & \\
\hline \multirow[t]{4}{*}{ Gender } & Male & $\mathrm{N}$ & 4 & 15 & 4 & 23 \\
\hline & & $\%$ & $17.4 \%$ & $65.2 \%$ & $17.4 \%$ & $100.0 \%$ \\
\hline & Female & $\mathrm{N}$ & 3 & 9 & I & 13 \\
\hline & & $\%$ & $23.1 \%$ & $69.2 \%$ & $7.7 \%$ & $100.0 \%$ \\
\hline \multirow[t]{2}{*}{ Total } & & $\mathrm{N}$ & 7 & 24 & 5 & 36 \\
\hline & & $\%$ & $19.4 \%$ & $66.7 \%$ & $13.9 \%$ & $100.0 \%$ \\
\hline
\end{tabular}

TABLE 2. Clinical characteristics and other findings of Kawasaki patients

\begin{tabular}{|c|c|c|}
\hline Principal criteria & $n=36$ & $\%$ \\
\hline Changes in oral mucosa & 34 & 94.4 \\
\hline Changes in extremities & 29 & 80.6 \\
\hline Polymorphous rash & 28 & 77.8 \\
\hline Bilateral non-purulent conjunctivitis & 26 & 72.2 \\
\hline Cervical lymphadenopathy & 23 & 63.9 \\
\hline \multicolumn{3}{|l|}{ Other } \\
\hline Perineal Desquamation & II & 30.6 \\
\hline Aseptic Meningitis & 4 & II.I \\
\hline Arthritis & 3 & 8.3 \\
\hline Respiratory infections & 2 & 5.5 \\
\hline Febrile convulsion & 2 & 5.5 \\
\hline Gallbladder Hydrops & 1 & 2.8 \\
\hline Redness at the site of the BCG scar & 1 & 2.8 \\
\hline Macrophage activation syndrome & 1 & 2.8 \\
\hline Anemia for age & 23 & 63.9 \\
\hline WBC count $>15.000 / \mathrm{mm} 3$ & 20 & 55.5 \\
\hline Platelet count $>450.000 / \mathrm{mm} 3$ & 26 & 72.2 \\
\hline Hypoalbuminemia & 4 & II.I \\
\hline Sterile Pyuria & II & 30.6 \\
\hline $\mathrm{ALT}>40 \mathrm{U} / \mathrm{L}$ & 20 & 55.5 \\
\hline
\end{tabular}

The mean time to diagnosis according to the duration of fever ranged from 4 to 20 days, with a mean of $7.69 \pm 3.79$ days. A total of 30 patients ( $83.3 \%$ ) were diagnosed within the first 10 days, and of the remaining 6 patients (aged 22-62 months), 3 were diagnosed with arthritis, I with gallbladder hydrops, and 2 with aseptic meningitis. Their condition improved after they received IVIG treatment, and none had coronary findings.

All patients had a high fever. The most common symptom was changes in oropharyngeal mucosa, occurring in $94.4 \%$ of the cases $(n=34)$, followed by changes in extremities in 29 patients (80.6\%), polymorphous rash in 27 patients (77.8\%), conjunctivitis in 26 patients (72.2\%), and lymphadenomegaly in 23 patients (63.9\%) (Table 2). In I patient, lymphadenopathy was in the submandibular region, and it was treated as infectious lymphadenitis.

Among the other findings, the most common was perineal desquamation, occurring in $30.6 \%$ of the patients, followed by aseptic meningitis (II.I\%), arthritis (8.3\%), gallbladder hydrops, macrophage activation syndrome (MAS), and redness in Bacillus Calmette-Guérin (BCG) vaccine scar (2.8\%) (Table 2). A male patient aged 9 months with hereditary spherocytosis was

\begin{tabular}{|c|c|c|c|c|c|}
\hline & & 0-II months & $12-60$ months & $60+$ month & \\
\hline \multirow[t]{2}{*}{ Incomplete } & $n$ & 5 & 8 & 4 & 17 \\
\hline & $\%$ & $29.4 \%$ & $47.1 \%$ & $23.5 \%$ & $100.0 \%$ \\
\hline \multirow[t]{2}{*}{ Complete } & $n$ & 2 & 16 & I & 19 \\
\hline & $\%$ & $10.5 \%$ & $84.2 \%$ & $5.3 \%$ & $100.0 \%$ \\
\hline \multirow[t]{2}{*}{ Total } & $n$ & 7 & 24 & 5 & 36 \\
\hline & $\%$ & $19.4 \%$ & $66.7 \%$ & $13.9 \%$ & $100.0 \%$ \\
\hline
\end{tabular}

TABLE 4. Comparison of echocardiography findings and laboratory values

\begin{tabular}{|c|c|c|c|}
\hline & $\begin{array}{l}\text { Positive Echo } \\
\text { Finding }(\mathrm{N}=12) \\
(\text { Mean } \pm \mathrm{SD})\end{array}$ & $\begin{array}{l}\text { Negative Echo } \\
\text { Finding }(N=24) \\
(\text { Mean } \pm S D)\end{array}$ & $p$ \\
\hline $\mathrm{WBC}\left(\times 1000 / \mathrm{mm}^{3}\right)$ & $17904.16 \pm 6057.29$ & $14070.00 \pm 5736.00$ & .07 \\
\hline $\mathrm{Hb}(\mathrm{g} / \mathrm{dL})$ & $10.2417 \pm 1.60593$ & $10.5000 \pm 0.81347$ & .97 \\
\hline $\begin{array}{l}\text { Platelet count } \\
\left(\times 1000 / \mathrm{mm}^{3}\right)\end{array}$ & $99500.08 \pm 240258.35$ & $268816.37 \pm 316800.79$ & .17 \\
\hline $\mathrm{CRP}(\mathrm{mg} / \mathrm{dL})$ & $|5| .8517 \pm 107.56330$ & $109.3079 \pm 68.57964$ & .47 \\
\hline $\operatorname{ALT}(I U / L)$ & $56.6667 \pm 32.49429$ & $50.0000 \pm 27.5807 \mid$ & .73 \\
\hline AST (IU/L) & $54.6667 \pm 69.90166$ & $51.1250 \pm 37.57116$ & .78 \\
\hline Albumin (g/dL) & $3.5525 \pm 0.31066$ & $3.6454 \pm 0.28261$ & .38 \\
\hline $\operatorname{ESR}(\mathrm{mm} / \mathrm{h})$ & $80.0833 \pm 28.93396$ & $83.7917 \pm 31.06792$ & .73 \\
\hline
\end{tabular}

TABLE 5. Comparison of Echo findings by age and fever duration

\begin{tabular}{|lcccc|}
\hline & $\begin{array}{c}\text { Positive Echo } \\
\text { Finding }(\mathbf{N}=12) \\
(\text { Mean } \pm \text { SD) }\end{array}$ & $\begin{array}{c}\text { Negative Echo } \\
\text { Finding }(\mathbf{N}=24) \\
(\text { Mean } \pm \text { SD) }\end{array}$ & Test & P \\
\hline $\begin{array}{l}\text { Age (months) } \\
\begin{array}{l}\text { Fever Duration } \\
\text { (days) }\end{array}\end{array}$ & $18.00 \pm 12.358$ & $35.25 \pm 19.501$ & Mann-Whitney U & $.008^{*}$ \\
\hline
\end{tabular}


initially diagnosed with urinary infection, but left coronary dilatation was seen in his ECHO. Eight patients with $\mathrm{KKD}$ at the time of diagnosis and had no ECHO findings were treated with IVIG therapy on the basis of laboratory findings consistent with AHA criteria, and the remaining patients developed desquamation in the extremities during follow-up.

Based on AHA diagnostic criteria, 19 patients were diagnosed with $C K D$, and 17 patients were diagnosed with KKD. cKD and iKD cases according to age groups are presented in Table 4.

$\mathrm{ECHO}$ findings were normal in 24 patients, whereas 12 patients showed pathological findings, 9 of whom were male. Five of the patients with iKD had ECHO findings. Mitral insufficiency was observed in three patients, but it disappeared in all the patients except in one during the follow-up. Nine patients $(25 \%)$ had pathology in the coronary arteries, and 8 of them were male. Four patients had dilatation in the left coronary artery, I had dilatation in the right coronary artery, I had an aneurysm in the bilateral coronary arteries ( $4.6-4.5 \mathrm{~mm})$, I had bilateral coronary artery dilatation, and 2 patients had increased echogenicity in the coronary arteries. There was no statistically significant relationship between $\mathrm{ECHO}$ findings and fever duration, WBC and platelet counts, and $\mathrm{Hb}, \mathrm{CRP}, \mathrm{ESR}, \mathrm{ALT}, \mathrm{AST}$, and albumin levels. However, age distribution revealed that there was a significant positivity in $\mathrm{ECHO}$ findings ( $p=.008$ ) (Tables 4 and 5).

All patients were given IVIG at a dose of $2 \mathrm{~g} / \mathrm{kg}$ over 12 hours and ASA at $80-100 \mathrm{mg} / \mathrm{kg} /$ day at an anticoagulant dose after the fever subsided. Seven patients received a second dose of IVIG because their fever did not subside, and 2 of them received pulse methylprednisolone because of persistent fever. One of them developed bilateral coronary dilatation, and the other (a male aged 5 years who was unresponsive to methylprednisolone therapy) showed no cardiac pathology; he was treated with additional cyclosporine A because he developed MAS. A total of 7 patients (19.4\%) were unresponsive to IVIG therapy.

\section{DISCUSSION}

$\mathrm{KD}$ ranks first among the acquired heart diseases during childhood in developed countries (8). Missed KD cases are thought to be responsible for $5 \%$ of fatal or nonfatal myocardial ischemia seen in angiography studies on individuals aged $<40$ years $(9$, 10). KD most commonly occurs in children aged $<5$ years, with $76 \%-90 \%$ of all KD cases occurring at age $<5$ years $(1,3-5,11-17)$. It is reported to be 1.5 times more common in males $(1,3-6)$. Similarly, $86.1 \%$ of our patients were aged $<5$ years, and the male-tofemale ratio was $1: 77$.

The etiology of the disease is still unknown; different infectious agents have been implicated, but no definite factor has been found. The incidence of KD tends to be 10 times higher in the siblings of children with KD than in the normal population, whereas this rate is $13.8 \%$ in identical twins (18). The SMAD5 gene, which may cause KD, has been reported to increase the risk of KD (19). The incidence of disease peaking during the winter and spring seasons, when bacterial and viral infections are common, appears to support this view $(20,21)$. Therefore, exposure to agents when there is genetic predisposition is thought to trigger vasculitis. In studies from different regions, seasonal distribution is variable, and it is reported to be more common in winter and spring (12-16, 20, 21). Thirteen of our cases (36.11\%) occurred during winter.

$\mathrm{KD}$ is a complex vasculitis manifesting itself with different signs and symptoms, where clinical findings change over time. The conventional diagnostic criteria may not be seen in all cases at the same time. In various studies, conjunctival hyperemia was observed in $61.4 \%-97.1 \%$ of KD cases, oral cavity lesions in $59.1 \%$ $97.1 \%$ of cases, cervical lymphadenopathy in $48.6 \%-70.8 \%$ cases, polymorphous rash in $66.7 \%-85.7 \%$ cases, and changes in the extremities in $50 \%-78.8 \%$ of cases (II-16). In our study, oral mucosal changes were observed in 34 cases (94.4\%), polymorphous rash in 27 (77.8\%), conjunctivitis in 26 (72.2\%), lymphadenomegaly in $23(63.9 \%)$, and changes in the extremities in 29 cases (80.6\%).

iKD cases have been reported to comprise $16.4 \%-56.6 \%$ of all patients with KD (I7,22-26). In their study, Tulloh et al. (5) reported that coronary artery involvement occurred in 19\% of all patients with KD, total cardiac complications occurred in $28 \%$ of them, and the risk of CAA was $39 \%$ higher in patients aged $<1$ year. In our study, 19 of our patients (52.8\%) were diagnosed with $\mathrm{CKD}_{1}$ and $17(47.2 \%)$ were diagnosed with iKD. There were only 7 patients aged $<12$ months, 2 of whom had cKD. Coronary involvement occurred in 5 patients among a total of 19 patients with iKD, and 2 of them were aged $<12$ months. In our study, I male patient aged $<12$ months with hereditary spherocytosis had coronary dilatation. The association of KD with hereditary spherocytosis has not been previously reported; therefore, we can consider this case just a coincidence. In our previous study conducted at the same center, $80.9 \%$ of the cases were diagnosed with CKD (21). The increase in the incidence of iKD cases can be attributed to the raised awareness about this disease and early diagnosis.

CAA is the most feared cardiac finding in KD. Although coronary artery involvement is a specific symptom in KD, myocarditis, pericardial effusion, and mitral and aortic valve regurgitation are also seen in acute and subacute phases during the clinical course of $\operatorname{KD}(1,3,6)$. AHA recommends that the coronary arteries be evaluated with a coronary artery z score according to body surface area. In addition, there is a different concept: if $\mathrm{ECHO}$ of the coronary arteries shows an internal lumen diameter $\leq 4 \mathrm{~mm}$ in patients aged $<5$ years, it is considered a localized dilatation or small aneurysm, whereas an internal lumen diameter between 4 and $8 \mathrm{~mm}$ is considered medium-sized aneurysm, and a diameter $\geq 8 \mathrm{~mm}$ is considered giant aneurysm. However, in patients aged $>5$ years, a diameter $<1.5$ times larger than that of the adjacent segment is defined as a small aneurysm, a diameter that is 1.5-4 times larger is considered a medium-sized aneurysm, and a diameter that is $>4$ times is considered a giant aneurysm (8). Apart from the appearance of CAA, brightness in the coronary lumen is also a characteristic finding of KD (7). AHA recommends that the first baseline $\mathrm{ECHO}$ be performed at the time of diagnosis in KD and then repeat $\mathrm{ECHOs}$ be performed between I and 2 weeks and a follow-up ECHO be performed between 4 and 6 weeks in uncomplicated patients $(1,6)$. All of our patients underwent $\mathrm{ECHO}$ at the time of diagnosis. In the first week, 5 patients had coronary involvement, 2 of whom had a medium-sized aneurysm and bilateral small aneurysm, I had left coronary artery dilatation, 2 had increased echogenicity (brightness), and 3 patients had mitral valve regurgitation. 
$\mathrm{ECHO}$ in the second week also revealed findings in 4 patients: 3 had dilatation of the left coronary artery and I had dilatation of the right coronary artery. Nine patients with coronary findings recovered during follow-up between I and 12 months.

Because KD is a type of vasculitis affecting all medium-sized arteries in the acute phase, the symptoms tend to vary widely, which include hepatitis, interstitial pneumonia due to affected bronchial arteries, abdominal pain with gastrointestinal tract involvement, vomiting, diarrhea, gall bladder hydrops, meningeal irritability, aseptic meningitis, myocarditis, pericarditis, valvulitis in the heart, pyuria in the urinary tract, pancreatitis, lymphadenopathy, and arthritis (1,3,4, 8, 12-17). Perianal desquamation and $B C G$ scar enduration are also found in patients with $K D(1,6,15$, 27). Among them, the most common finding in our patients was perianal desquamation, which occurred in II patients. A total of 10 patients had hepatitis, 7 had pyuria, 4 had aseptic meningitis, 3 had respiratory tract infection and arthritis, and I had gallbladder hydrops, MAS, and BCG scar induration.

The prevalent view is that IVIG infusion therapy reduces coronary artery involvement by up to $5 \%$ and that IVIG therapy given within the first 7 days is more effective in reducing the risk of CAA. After IVIG therapy, the fever usually decreases, and the symptoms regress. If fever persists after 36 hours after IVIG therapy, the second dose of IVIG or pulse prednisolone treatment is recommended. About 10\%-20\% of patients with KD did not respond to IVIG treatment $(I, 6,8,17,28)$. Of this number, $19.4 \%$ were unresponsive to IVIG therapy. One of our patients who did not respond to IVIG therapy had bilateral aneurysms, and the other had dilatation of the left coronary artery. In addition, another of our patients who did not respond to IVIG therapy had MAS.

MAS is a rare but fatal complication of KD. It has been reported that MAS is seen in $0.1 \%-1.9 \%$ of patients with $K D$, and elevated ALT, AST, triglycerides, ferritin, and decreased fibrinogen are important in the diagnosis of MAS $(29,30)$. The recommended drugs in the treatment of MAS include pulse methylprednisolone, infliximab, anakinra, and cyclosporin A. Our patient also recovered after treatment with cyclosporine $A$.

KD should always be kept in mind while evaluating the symptoms in children presenting with prolonged high fever, $\mathrm{ECHO}$ should be performed when necessary, and the disease should be treated promptly before patients develop any possible complications.

Ethics Committee Approval: Ethics committee approval was received for this study from the ethics committee of Okmeydanı Training and Research Hospital (approval date: 08/0I/2019, approval number: 4867077I514.10).

Informed Consent: N/A

Peer-review: Externally peer-reviewed.

Author contributions: Concept - Y.E., A.I.; Design - Y.E., O.F.B.; Supervision - Y.E., A.I.; Resource - Y.E., C.E.; Materials - S.S., A.I., E.T.; Data Collection and/or Processing - Y.E., S.S., C.E., E.T., A.I.; Analysis and/or Interpretation - Y.E., A.I., O.F.B.; Literature Search - S.S., E.T., C.E.; Writing - Y.E.; Critical Reviews - A.I., O.F.B.
Conflict of Interest: Authors have no conflicts of interest to declare.

Financial Disclosure: The authors declared that this study has received no financial support.

\section{REFERENCES}

I. Newburger JW, Takahashi M, Gerber MA, Gewitz MH, Tani LY, Burns JC, et al. Committee on Rheumatic Fever, Endocarditis, and Kawasaki Disease, Council on Cardiovascular Disease in the Young; American Heart Association; American Academy of Pediatrics. Circulation 2004; 135: e927-99.

2. Kawasaki T. Acute febrile mucocutaneous syndrome with lymphoid involvement with specific desquamation of fingers and toes in children. Arerugi 1967; 16(3): 178-222.

3. Makino N, Nakamura Y, Yashiro M, Kosami K, Matsubara Y, Ae R, et al. Nationwide epidemiologic survey of Kawasaki disease in Japan, 2015-2016. Pediatr Int 2019; 61(4): 397-403. [Crossref]

4. Holman RC, Belay ED, Christensen KY, Folkema AM, Steiner CA, Schonberger LB. Hospitalizations for Kawasaki syndrome among children in the United States, 1997-2007. Pediatr Infect Dis J 20I0; 29(6): 483-8. [Crossref]

5. Tulloh RMR, Mayon-White R, Harnden A, Ramanan AV, Tizard EJ, Shingadia $D$, et al. Kawasaki disease: a prospective population survey in the UK and Ireland from 2013 to 2015. Arch Dis Child 2019; 104(7): 640-6. [Crossref]

6. McCrindle BW, Rowley AH, Newburger JW, Burns JC, Bolger AF, Gewitz M, et al. American Heart Association Rheumatic Fever, Endocarditis, and Kawasaki Disease Committee of the Council on Cardiovascular Disease in the Young; Council on Cardiovascular and Stroke Nursing; Council on Cardiovascular Surgery and Anesthesia; and Council on Epidemiology and Prevention. Diagnosis, Treatment, and Long-Term Management of Kawasaki Disease: A Scientific Statement for Health Professionals from the American Heart Association. Circulation 2017; 135(17): e92799. [Crossref]

7. Chbeir D, Gaschignard J, Bonnefoy R, Beyler C, Melki I, Faye A, et al. Kawasaki disease: abnormal initial echocardiogram is associated with resistance to $\mathrm{IV} \mathrm{Ig}$ and development of coronary artery lesions. Pediatr Rheumatol Online J 2018; 16(I): 48. [Crossref]

8. De Graeff N, Groot N, Ozen S, Eleftheriou D, Avcin T, Bader-Meunier $B$, et al. European consensus-based recommendations for the diagnosis and treatment of Kawasaki disease - the SHARE initiative. Rheumatology (Oxford) 2019; 58(4): 672-82. [Crossref]

9. JCS Joint Working Group. Guidelines for diagnosis and management of cardiovascular sequelae in Kawasaki disease (JCS 2013). Digest version. Circ J 20l4; 78(I0): 2521-62. [Crossref]

10. Rizk SR, El Said G, Daniels LB, Burns JC, El Said H, Sorour KA, et al. Acute myocardial ischemia in adults secondary to missed Kawasaki disease in childhood. Am J Cardiol 20I5; II5(4): 423-7. [Crossref]

II. Binder E, Griesmaier E, Giner T, Sailer-Höck M, Brunner J. Kawasaki disease in children and adolescents: clinical data of Kawasaki patients in a western region (Tyrol) of Austria from 2003-2012. Pediatr Rheumatol Online J 2014; 12(I): 37. [Crossref]

12. de La Harpe M, di Bernardo, Hofer M, Sekarski N. Thirty Years of Kawasaki Disease: A Single-Center Study at the University Hospital of Lausanne. Front Pediatr 2019; 7: II. [Crossref]

13. Gülhan B, Kesici S, Beken S, Cilsal E, Kale G, Alehan D, et al. Varying clinical features of Turkish Kawasaki disease patients. Turk J Pediatr 2012; 54(I): I-6.

14 Kayıran SM, Dindar A and Gurakan B. An evaluation of children with Kawasaki disease in Istanbul: a retrospective follow-up study. Clinics (Sao Paulo) 2010; 65(I2): 126I-5. [Crossref]

15. Uysal F, Bostan OM, Celebi S, Uysal B, Hamitoglu S, Cil E. Outcomes of Kawasaki Disease: A Single-Center Experience. Clin Pediatr (Phila) 2015; 54(6): 579-84. [Crossref] 
16. Ozdemir H, Ciftçi E, Tapisiz A, Ince E, Tutar E, Atalay S, et al. Clinical and epidemiological characteristics of children with Kawasaki disease in Turkey. J Trop Pediatr 2010; 56(4): 260-2. [Crossref]

17. Fernandez-Cooke E, Barrios Tascón A, Sánchez-Manubens J, Antón J, Grasa Lozano CD, Aracil Santos J, et al. Epidemiological and clinical features of Kawasaki disease in Spain over 5 years and risk factors for aneurysm development. (20II-2016): KAWA-RACE study group. PLoS One 2019; 14(5): e0215665. [Crossref]

18. Uehara R, Yashiro M, Nakamura Y, Yanagawa H. Kawasaki disease in parents and children. Acta Paediatr 2003; 92(6): 694-7.[Crossref]

19. Cho JH, Han MY, Cha SH, Jung JH, Yoon KL. Genetic polymorphism of SMAD5 is associated with Kawasaki disease. Pediatr Cardiol 2014; 35(4): 60l-7. [Crossref]

20. Huang WC, Huang LM, Chang IS, Chang LY, Chiang BL, Chen PJ, et al. Epidemiologic Features of Kawasaki Disease in Taiwan, 20032006. Pediatrics 2009; 123(3): e40I-5. [Crossref]

21. Arat C, Acar Y, Turkmenoğlu Y, Sayar T, Hamilçıkan SB, Sazak S, et al. Kawasaki hastalığı: 2 l olgunun değerlendirilmesi. Cukurova Med J 2016; 4I(I): 97-104. [Crossref]

22. Kato H, Sugimura T, Akagi T, Sato N, Hashino K, Maeno Y, et al. Longterm consequences of Kawasaki disease. A I0- to 2l-year follow-up study of 594 patients. Circulation 1996; 94(6): 1379-85. [Crossref]

23. Sudo D, Monobe Y, Yashiro M, Mieno MN, Uehara R, Tsuchiya K, et al. Coronary artery lesions of incomplete Kawasaki disease: a nationwide survey in Japan. Eur J Pediatr 2012; 17I(4): 65I-6. [Crossref]
24. Yellen ES, Gauvreau K, Takahashi M, Burns JC, Shulman S, Baker AL, et al. Performance of 2004 American Heart Assoociation recommendations for treatment of Kawasaki Disease. Pediatrics 2010; 125(2): e234-4l. [Crossref]

25. Yeo Y, Kim T, Ha K, Jang G, Lee J, Lee K, et al. Incomplete Kawasaki disease in patients younger than I year of age: a possible inherent risk factor. Eur J Pediatr 2009; 168(2): 157-62. [Crossref]

26. Manlhiot C, Christie E, McCrindle BW, Rosenberg H, Chahal N, Yeung RS. Complete and incomplete Kawasaki disease: two sides of the same coin. Eur J Pediatr 2012; 17I(4): 657-62. [Crossref]

27. Falcini F, Ozen S, Magni-Manzoni S, Candelli M, Ricci L, Martini G, et al. Discrimination between incomplete and atypical Kawasaki syndrome versus other febrile disease in childhood: resuts from an international registry-based study. Clin Exp Rheumatol 2012; 30(5): 799-804

28. Chan $H$, Chi $H$, You $H$, Wang $M$, Zhang $G$, Yang $H$, et al. Indirect -comparison meta-analysis of treatment options for patients with refractory Kawasaki disease. BMC Pediatr 2019; 19(I): 158. [Crossref]

29. Latino GA, Manlhiot C, Yeung RS, Chahal N, McCrindle BW. Macrophage activation syndrome in acute phase of Kawasaki disease. J Pediatr Hematol Oncol 2010; 32(7): 527-3I. [Crossref]

30. Wang W, Gong F, Zhu W, Fu Z, Zhang Q. Macrophage activation syndrome in Kawasaki Disease: More common than we thought? Semin Arthritis Rheum 2015; 44(4): 405-10. [Crossref] 